\title{
Un enigma sobre el enigma. Safo de Lesbos y el acertijo de la carta
}

\section{Mariana Gardella Hueso}

Consejo Nacional de Investigaciones Científicas y Técnicas - Universidad de Buenos Aires, Argentina.

Recibido el 15 de octubre de 2018; aceptado el 20 de diciembre de 2018.

\begin{abstract}
Resumen
Los enigmas tradicionales poseen una importante función filosófica, ya que muestran los límites del conocimiento sobre el mundo y del conocimiento de sí. Desde una perspectiva filosófica, analizaré en este trabajo el enigma de la carta que aparece en Safo, la comedia de Antífanes (Ateneo, Banquete de los sabios X.450e-451 b = fr. 194 KA). Para ello presentaré, en primer lugar, algunas observaciones preliminares sobre la tradición de los enigmas en Grecia antigua, deteniéndome principalmente en las definiciones de "enigma" ofrecidas por Aristóteles y Clearco, en las estrategias utilizadas para ocultar la solución y en la conexión entre los acertijos y el humor. En segundo lugar, examinaré algunos fragmentos de comedias en los que aparecen mujeres intelectuales conocidas o mujeres anónimas pronunciando enigmas. Estas fuentes proporcionarán un marco para analizar, en tercer lugar, el enigma que aparece en la comedia de Antífanes. Aunque se ha indicado que este acertijo muestra la importancia de la escritura epistolar y la práctica de la lectura silenciosa, me gustaría sugerir que también podría referir a los enigmas en sí mismos y al modo en que estos se transmiten y resuelven.
\end{abstract}

\section{A riddle on the riddle}

\section{Sappho of Lesbos and the riddle on the letter}

\begin{abstract}
Traditional riddles have an important philosophical function, since they show both the limits of the knowledge about the world and self-knowledge. From a philosophical perspective, in this paper I will analyze the riddle on the letter that appears in Antiphanes' comedy Sappho (Athenaeus, Deipnosophistae X.450e-451 b = fr. 194 KA). In order to do this, I will present first some preliminary remarks on the riddle tradition in Ancient Greece, focusing mainly on Aristotle and Clearchus' definitions of the riddle, the recurring devices using to disguise the solutions and the connection between riddles and humor. Then, I will examine some fragments of comedies in
\end{abstract}

Palabras clave

conocimiento enigma escritura Safo

\section{Keywords}

knowledge riddle Sappho writing 
1. No haré referencia a los enigmas de otras culturas antiguas. Al respecto, véase los estudios reunidos por Hasan-Rokem y Shulman (1996).

2. Las traducciones de este trabajo son de mi autoría. Hay una versión más extensa del enigma de la Esfinge proporcionada por Asclepíades de Tragilo y preservada por Ateneo, Banquete de los sabios X.456b. Al respecto, cfr. Katz (2006: 8-10). Véase también Antología palatina XIV.64. En este trabajo, empleo los términos "enigma" y "acertijo" como sinónimos.

3. De acuerdo con la opinión de Vernant (1990: 118-119), "al igual que su propio discurso, al igual que el mensaje del oráculo, Edipo es doble, enigmático [...]. En todo aspecto - -social, religioso y humano- la figura de Edipo resulta ser lo opuesto de lo que, como líder de la ciudad, aparentaba ser". Cfr. Beta (2016: 15-24). La paradójica tensión entre la sagacidad que le permite a Edipo resolver el enigma y la completa ignorancia sobre quién es constituye uno de los puntos clave de la tragedia. En efecto, Edipo es caracterizado por el coro como "quien tenía conocimiento

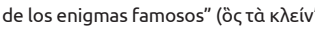
aivivpat' n̋ $\delta \varepsilon ı)$ (1525), a pesar de que es incapaz de comprender el mensaje de

Tiresias, a quien acusa de decir palabras enigmáticas y poco claras ('́ç návт'

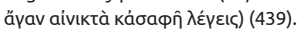

which well-known intellectual women or anonymous women appear on the scene uttering riddles. These sources will provide a frame to analyze, in the third place, the riddle of Antiphanes' Sappo. Although it has been noticed that the solution of the riddle shows the importance of epistolary writing and the practice of silent reading, I would like to suggest that it could also refer to riddles themselves and to the way in which they are transmitted and solved.

\section{Introducción}

En el Tractatus logico-philosophicus Wittgenstein sostiene: Das Rätsel gibtes nicht (6.5). Esta afirmación, curiosamente enigmática, se justifica en los límites que el filósofo impone al lenguaje: sólo se puede hablar de lo que puede ser dicho mediante proposiciones con sentido - i.e. verdaderas o falsas, según se desprenda de su comparación con el mundo-, mientras que es mejor callar sobre cuantas cosas sólo sea posible enunciar pseudo-proposiciones -i.e. proposiciones sin sentido que no dicen, sino que muestran, y cuya verdad o falsedad es imposible determinar-. El enigma podría ser comprendido como una pseudo-proposición que oculta su referente de manera tal que, antes de conocer la solución, es imposible comprender a qué remite, por lo que posee sólo un sentido promisorio. Aunque estas observaciones sobre el enigma responden al modo particular en que Wittgenstein concibe el lenguaje y su relación con el mundo, constituyen un sugerente punto de partida para reflexionar sobre la naturaleza y los alcances de los enunciados enigmáticos en la cultura griega antigua. ${ }^{1}$

El juego entre ocultamiento y desvelamiento constituye el corazón de todo enigma. Como ha señalado Pucci (1996: 9), el enigma es un dispositivo lingüístico que esconde y al mismo tiempo revela, apunta siempre a "lo oculto que está a la vista". En efecto, la solución de la mayor parte de los acertijos consiste, o bien en entidades o fenómenos de la experiencia ordinaria, o bien en personajes míticos que forman parte del acervo cultural compartido. A modo de ejemplo, se puede citar el famoso acertijo de la Esfinge: “¿Qué cosa es lo que, a pesar de tener una única voz, cuenta con

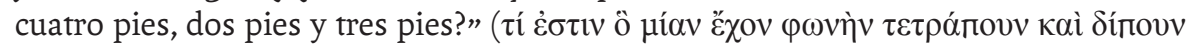

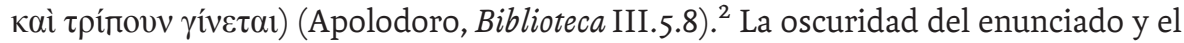
denodado esfuerzo que implica desentrañar su sentido contrastan con la banalidad de la solución: un hombre que atraviesa las distintas etapas de la vida. Aquello que los enigmas ocultan, entonces, es algo evidente, algo que se conoce. Cuando estos se resuelven, la aporía inicial conduce a la sorpresa y el asombro: al encontrar la solución, se puede observar, desde una nueva perspectiva que inviste de maravilla lo ordinario y familiar, aquello que se presumía conocer, lo que deja en evidencia la precariedad e inestabilidad del conocimiento que tenemos sobre el mundo.

El desafío intelectual que proponen los enigmas tiene a su vez un impacto existencial, como se aprecia en el caso de Edipo (Hasan-Rokem y Shulman, 1996: 3-5). Aunque este descubre la solución del acertijo citado, se muestra incapaz de resolver el enigma de su propia identidad, a cuya respuesta llega cuando se reconoce como lo opuesto de lo que aparentaba ser. ${ }^{3}$ Por otra parte, la contradicción entre ser y uno y ser múltiple que establece el enigma de la Esfinge -y que es propia de otros enunciados enigmáticos, como se verá infra - refleja la verdadera condición del héroe, quien descubre que es extranjero y nativo de Tebas, rey de la ciudad y forajido, hijo y esposo de Yocasta, padre y hermano de sus propios hijos (Rokem, 1996: 261-268; Segal, 1999: 216-217, 236-238). Así, la experiencia del enigma constituye un doble movimiento que amplía tanto el conocimiento sobre el mundo que se oculta para, transformado, volver a manifestarse, como el conocimiento de sí, dado que la respuesta de muchos acertijos modifica existencialmente a quien se propone resolverlos. 
En este trabajo, me propongo explorar la estructura y alcance del decir enigmático en Grecia antigua desde una perspectiva filosófica. Dado que las fuentes son numerosas, me concentraré particularmente en el acertijo que se atribuye a Safo en la comedia homónima escrita por Antífanes. ${ }^{4}$ Aunque la solución del enigma pone en evidencia la irrupción del género epistolar y la práctica de la lectura silenciosa, sugeriré que, de cierto modo, también hace referencia al modo en que los enigmas se transmiten y resuelven. Para ello presentaré, en primer lugar, algunas observaciones preliminares sobre los enigmas en Grecia: analizaré las definiciones de este género ofrecidas por Aristóteles y Clearco de Solos, revisaré algunos recursos frecuentes para su composición - la paradoja, la metonimia, la analogía y la polisemia- y comentaré brevemente el uso simposial de los acertijos y su relación con el humor. En segundo lugar, consideraré algunos pasajes de comedias en los que mujeres intelectuales conocidas o mujeres anónimas aparecen en escena pronunciando enigmas. Estas fuentes aportarán un marco de referencia para analizar, en tercer lugar, el enigma que Antífanes atribuye a Safo. Revisaré las interpretaciones clásicas sobre este acertijo y propondré una lectura alternativa que permita explorar la relación entre el modo de comunicación de la epístola y el modo de comunicación del enigma.

\section{La tradición del enigma en Grecia}

Para comprender el valor del enigma que Antífanes adjudica a Safo, es preciso presentar algunas observaciones generales sobre las características del decir enigmático en Grecia antigua. En griego se emplean usualmente dos términos para referir al enigma: aîvi $\gamma \mu \alpha$ y $\gamma \rho \tilde{i} \varphi$ os. Este último designa también la cesta hecha de juncos utilizada por los pescadores, a partir de lo que se podría inferir que los enigmas eran concebidos como dispositivos que tenían la función de atrapar a quienes no podían resolverlos. En un escolio a Compra de vidas de Luciano de Samósata, se indica que

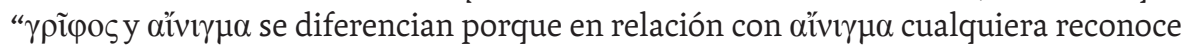
que ignora, pero en relación con $\gamma$ ĩ $\varphi$ o $\zeta$ se ignora, a pesar de que se cree saber". ${ }^{5} \mathrm{El}$ ejemplo de alvi $\gamma \mu \alpha$ ofrecido en ese contexto es el que la Esfinge lanzó a Edipo, el de

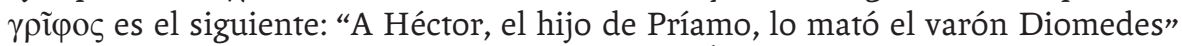

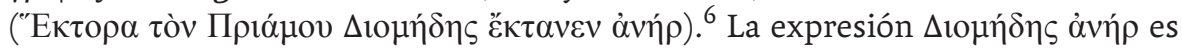
ambigua, ya que puede referir tanto al "varón Diomedes", i.e. el héroe aqueo que no mató a Héctor, como al "varón de Diomeda", i.e. Aquiles, el asesino del hijo de Príamo. Esto es posible porque el término $\Delta 10 \mu \eta ́ \delta \eta\rceil$ puede ser, o bien la forma en nominati-

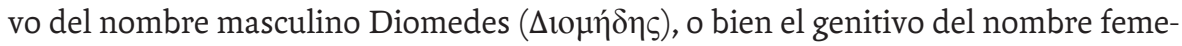

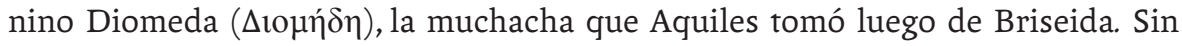
embargo, si nos atenemos a las fuentes antiguas, no existe una distinción neta entre $\alpha$ aiv $\gamma \mu \alpha$ y $\gamma \rho \tilde{i} \varphi$ os. Ambos términos se utilizan usualmente de forma intercambiable, como si fueran sinónimos. ${ }^{7}$

Ejemplos como el recién citado han llevado a establecer una distinción entre enigmas en sentido estricto y en sentido amplio, al cual pertenecerían las charadas y otros juegos de palabras semejantes. ${ }^{8}$ Sin embargo, esta propuesta presenta un problema: encontrar una definición precisa de enigma que sirva como base de la clasificación. Llamativamente, el carácter enigmático de estos enunciados lingüísticos se manifiesta de forma plena en la imposibilidad de hallar una definición satisfactoria del género. ${ }^{9}$ La primera caracterización ha sido ofrecida por Aristóteles y ha influenciado profundamente los estudios sobre el tema. Esta hace énfasis en dos aspectos: la vinculación del enigma con la metáfora y con las nociones en apariencia irreconocibles. En efecto, en el marco del estudio de la expresión ( $\left.\lambda \varepsilon_{\varepsilon} \xi 1 \zeta\right)$ desarrollado en Poética, se establece que el poeta debe encontrar la manera de formular expresiones claras que, sin embargo, no sean banales. La claridad se logra
4. Entiendo que se trata de una atribución y no de un enigma compuesto originariamente por Safo. Al respecto, cfr. Ceccarelli (2004: 18-19).

5. Escolio a Luciano, Compra de vidas

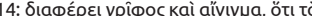

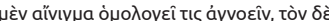

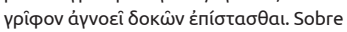
este testimonio, cfr. Luz (2013: 97). 6. Este enigma también aparece en Antología palatina XIV.18.

7. Luz (2013: 98). Una opinión diferente sostiene Konstantakos (2004: 120), quien señala que aîvirupa refiere a los enigmas en sentido estricto, mientras que ypī es un concepto más amplio que incluye otros juegos con palabras. Sobre las apariciones y usos de los términos aîvivu y үpîథo̧, véase Berra (2008: 75-269).

8. Esta distinción es sugerida por Buffière (1970: 45-49) a los fines de clasificar los epigramas enigmáticos transmitidos en el libro decimocuarto de Antología palatina, pero podría hacerse extensiva al resto de los enigmas transmitidos en otras fuentes griegas antiguas. Más recientemente, Kaivola-Bregenhøj (2001) ha propuesto una clasificación más compleja que comprende enigmas en sentido estricto, enigmas literarios, enigmas visuales, diverso tipo de preguntas, problemas y parodias. 9. Por esta razón son numerosas y disímiles las definiciones de "enigma" que se ofrecen en la literatura especializada. Sólo a modo de ejemplo se puede citar la clásica definición propuesta por Taylor (1943: 129), deudora en cierta medida de la definición de Aristóteles que se tratará infra: "El verdadero enigma o el enigma en sentido estricto compara un objeto con otro objeto completamente diferente. Su esencia consiste en la sorpresa que produce la solución: el oyente percibe que ha malinterpretado por completo lo que se le ha dicho". Más tarde, Taylor redefinió los enigmas en sentido estricto como "descripciones de objetos en términos que sugieren algo completamente diferente" (1951:1). 
10. No obstante, Aristóteles reconoce que "a partir de los enigmas que han sido bien formulados, es posible extraer metáforas logradas, pues las

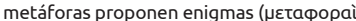
vàp aívítrovtal), de manera que es evidente que en los enigmas hay buenas metáforas" (Retórica Ill.2.1405b1-5).

11. Cfr. Aristóteles, Retórica III.2.1405b1; Plutarco, Banquete de los siete sabios 154b12; Demetrio de Siria, Sobre la elocución 102; Siriano, Comentario al Sobre las formas de Hermógenes 36.12-14 y Juan de Sicilia, Comentario al Sobre las formas de Hermógenes 199.30-200.2. Ateneo transmite una versión diferente del enigma en forma de dístico, ya que al hexámetro agrega un pentámetro: "tan íntimamente soldados quedaban que se hacían

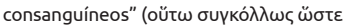
бúvaına noıहî) (X.452b10). La referencia a la consanguinidad permite pensar que la aplicación de las ventosas podría haber estado acompañada de la realización de incisiones en la piel o del uso de sanguijuelas que provocarían el sangrado. Cfr. Antología palatina XIV.54. Para una presentación general de Cleobulina y sus enigmas, véase Matelli (1997), y Gardella y Juliá (2018).

12. Para la traducción de los enigmas de Antología palatina, sigo la edición de Beckby (1958). Como ejemplo adicional se puede citar el enigma del eunuco mencionado por Platón en República para referir al ámbito sensible, un intermedio entre ser y no ser cuya característica más notable es la co-presencia de propiedades

opuestas: "Varón no varón, viendo y no viendo a un pájaro no pájaro, que estaba posado y que no estaba posado en un tronco no tronco, lo golpea y no lo golpea con una piedra no piedra. De otra manera: varón no varón, pero sin embargo varón -el eunuco-, golpeando con una piedra no piedra - la piedra pómez-a un pájaro no pájaro, pero sin embargo pájaro - un murciélago-, que estaba posado en un tronco no tronco - una caña-, me arruina: el eunuco al murciélago en una caña con una piedra pómez" (Escolio a Platón, República V.479c).

13. Sobre este tema, cfr. Luz (2013: 85-91). 14. El enigma hace referencia al reemplazo de huesos de cervatillo por huesos de burro para la fabricación de la flauta porque estos últimos sonaban mejor.

15. Véase otros ejemplos en Antología palatina XIV.21, 37, 53-54.

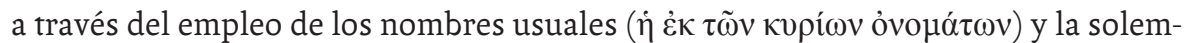

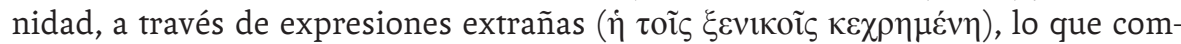
prende palabras extranjeras, metáforas y alargamientos (22.1457a33-1458a25). No obstante, la utilización excesiva de estos recursos puede comprometer la claridad del discurso y volverlo confuso. Por ejemplo, si sólo se emplean metáforas, lo que se dice puede adoptar el aspecto de un enigma. ${ }^{10}$ La metáfora es definida por Aristóteles como "el desplazamiento hacia una cosa del nombre que corresponde a otra, ya sea del género a la especie, de la especie al género, de una especie a otra especie, o por analogía" (22.1457b6-9). El enigma se vale de este desplazamiento con el objetivo de "hacer combinaciones imposibles para mencionar cosas que realmente

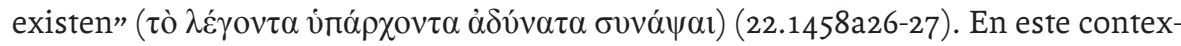
to se menciona como ejemplo el enigma de las ventosas de Cleobulina de Lindos, una eximia compositora de acertijos: "vi a hombre soldar con fuego bronce a hom-

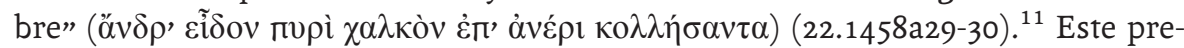
senta una metáfora adecuada formulada a partir del desplazamiento entre dos ítems que pertenecen al mismo género: la soldadura de bronce realizada con fuego por el herrero y la aplicación de ventosas calientes del mismo material sobre el cuerpo de los pacientes por parte del médico. Tanto en la aplicación de la ventosa sobre la piel como en la de un metal sobre una superficie se añade algo, de ahí que ambas actividades puedan recibir el nombre de "soldadura" (кó $\lambda \lambda \eta \sigma ı \varsigma)$.

De acuerdo con la definición ofrecida por Aristóteles, los enigmas permiten referir a cosas del mundo a través de la combinación de nociones o afirmaciones contrarias o contradictorias. En el ya citado enigma de la Esfinge, se presenta una combinación paradójica de nociones - que una misma persona tenga dos, tres y cuatro pies-que refiere, no obstante, a una entidad realmente existente -un hombre que atraviesa las distintas etapas de la vida-. Algo similar se observa en el enigma del silencio: "No hables y dirás mi nombre. Pero, ¿es necesario que hables? / Entonces, una vez más, gran sorpresa: hablando dirás mi nombre" (Antología palatina XIV.22). ${ }^{12}$ Esta característica hace que los enigmas se asemejen a ciertas paradojas, calificadas usualmente como "erísticas", cuya función es presentar un enunciado contradictorio que mueva al pensamiento a analizar algún fenómeno, como ocurre con las conocidas paradojas del movimiento formuladas por Zenón de Elea. Desde esta perspectiva, la intriga que generan los enigmas se transforma también en motor que impulsa a pensar.

Además de la contradicción, se destacan tres recursos frecuentes en la formulación de enigmas. ${ }^{13}$ Por una parte, el empleo metonímico de nombres que se aprecia, por ejemplo, en el enigma de la flauta de Cleobulina en el que por metonimia se llama a la flauta "burro muerto" y se presenta la idea paradójica de que un animal que ya no vive pueda aún patear: "con la pata y la pezuña, un burro muerto me golpeó la oreja"

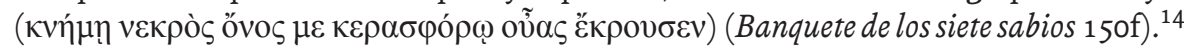
El mismo recurso es empleado en el enigma de Níobe, donde se dice que sus hijos, comparados con los doce ojos de la Escila de seis cabezas, fueron asesinados por el sol y la luna, i.e. Apolo y Ártemis:

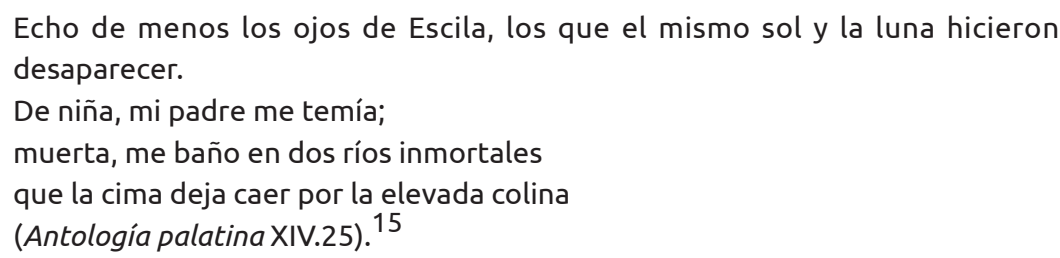

Para la composición de enigmas también es habitual el uso de analogías, como se ve en el enigma del año de Cleobulina en el que se establece una comparación entre 
el año, los meses y los días, y un padre, sus hijos y sus nietos: "uno el padre, doce

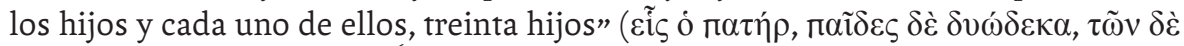
$\dot{\varepsilon} \kappa \alpha ́ \sigma \tau \omega ~ \pi \alpha i ̃ \delta \varepsilon \varsigma \tau \rho t \alpha ́ \kappa o v \tau \alpha) .{ }^{16}$ Por último, es frecuente el uso de palabras polisémicas, como se aprecia en el enigma del humo en el que se emplea el término кov́pars,

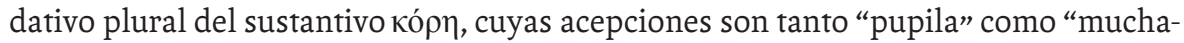
cha": "Soy hijo negro de padre blanco, pájaro sin alas / que vuela hasta las nubes del cielo. / Engendro lágrimas libres de dolor en las pupilas que se me acercan, / apenas nazco me disuelvo en el aire" (Antología palatina XIV.5).

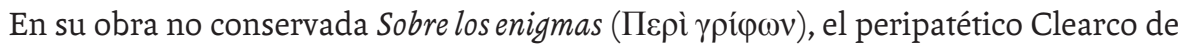
Solos aporta una definición alternativa de "enigma":

\section{Un enigma es un problema entretenido que demanda encontrar una solución a través de una investigación por medio de la inteligencia, aunque el enigma arrojado sea dicho con la intención de obtener una distinción o provocar un daño

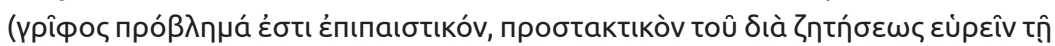

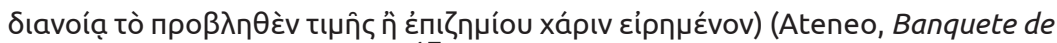 los sabios $448 \mathrm{C}=$ fr. 86 Wehrli). ${ }^{17}$}

Esta definición es importante por dos motivos: por una parte, presenta el enigma como un problema y enfatiza así su capacidad para desafiar la inteligencia. Por este motivo, Clearco habría dicho que "la solución de los enigmas no es ajena a la filosofía y con ellos los antiguos hacían una demostración de su educación". ${ }^{18}$ Por otra parte, al presentarlos como problemas entretenidos, Clearco realza su rasgo humorístico. En efecto, los acertijos eran pronunciados en los banquetes como parte de los entretenimientos que tenían lugar luego de la cena y del ofrecimiento de las libaciones: "se dice que los enigmas son preguntas oscuras arrojadas en los simposios". ${ }^{19}$ Quienes los resolvían eran premiados con coronas o tortas, y quienes no lograban hallar la respuesta debían cumplir una prenda. Esto explica por qué en Banquete de los sietes sabios de Plutarco se dice que los acertijos de Cleobulina eran lanzados a los comensales a modo de entretenimiento como si fueran los astrágalos con que se juega a la taba. ${ }^{20}$ No obstante, vale aclarar que no todos los enigmas eran pronunciados en contextos lúdicos con la intención de divertir. Por ejemplo, algunos eran empleados con fines pedagógicos para transmitir conocimientos sobre ciencia natural o sobre los mitos; ${ }^{21}$ otros, con fines religiosos, si se tiene en cuenta que ciertos mensajes transmitidos por los oráculos se expresaban a través de las técnicas y recursos empleados para la composición de enigmas. ${ }^{22}$ La relación entre enigma y humor es señalada por Pólux, quien sostiene que la diferencia entre

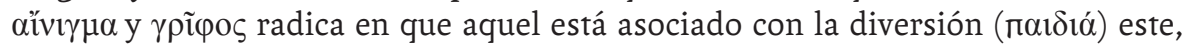
con la seriedad ( $\sigma \pi \circ \delta \delta \eta ́) ~(6.107)$. En efecto, junto con las paradojas, acrósticos, anagramas, palíndromos y lipogramas, aquellos se pueden agrupar en lo que actualmente se denomina con el neologismo $\tau \varepsilon \chi v o \pi \alpha i ́ \gamma v 1 \alpha$, i.e. la técnica $(\tau \varepsilon \dot{\varepsilon} \chi v \eta)$ de elaborar juegos ( $\pi \alpha i ́ \gamma v 1 \alpha)$ por medio del lenguaje. ${ }^{23}$ La semejanza que guardan con los juegos se observa manifiestamente en los enigmas que involucran juegos con pala-

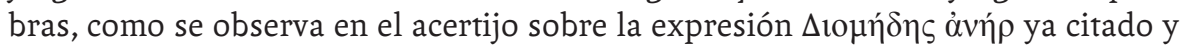
en el acertijo sobre las partes del animal en el que, de forma progresiva y a través de la supresión de la letra inicial de la palabra, se hace referencia al pie (пои́s), a la oreja (oũ $)$, al cerdo (ṽ $\varsigma$ ) y al número doscientos que se simboliza a través de la letra sigma $(\sigma)$ :

Soy de los animales una parte que busca el suelo;

si me quitas sólo una letra, de la cabeza una parte me vuelvo;

si me quitas otra, animal otra vez seré;

si también otra, no me encontrarás sólo como uno, sino como doscientos

(Antología palatina XIV.105). ${ }^{24}$
16. Suda, s.v. Cleobulina. Diógenes Laercio atribuye este acertijo a Cleobulo (I.91). Cfr. Estobeo I.8.37 y Antología palatina XIV.101.

17. Sobre esta definición, cfr. Guichard (2010: 286-288).

18. Ateneo, Banquete de los sabios 457c (= fr. 63 Wehrli): tŵv ypí $\omega$ wv ì

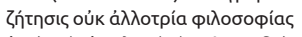

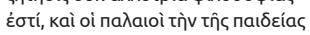

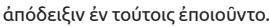

19. Escolio a Aristófanes, Avispas 20 (= fr.

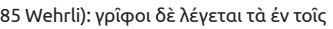

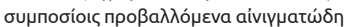
Zntńnata. Cfr. Ateneo, Banquete de los sabios X.458f-459a. Sobre la dimensión humorística de los enigmas, cfr. Potamiti (2015: 134). Sobre el uso de enigmas en banquetes, cfr. Beta (2009: 97-102).

20. Plutarco, Banquete de los sietes sabios 148d-e: "Pues los usa (sc. Cleobulina) algunas veces para jugar, como los astrágalos, y los lanza a quienes le salen al paso. Además, posee una asombrosa sensatez, pensamiento político y carácter filantrópi-

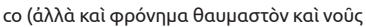

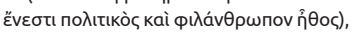
y hace a su padre un gobernante más apacible y popular ante los ciudadanos". La presencia de Cleobulina en el simposio de Plutarco abre el interrogante sobre la asistencia de las mujeres a este tipo de eventos. En contra de lo que se ha creído usualmente, hay evidencia que indica que la participación de las mujeres en los banquetes de varones no era inusual y que incluso existían banquetes sólo de mujeres, según defiende Burton (1998: 143-165). 21. Sobre este poco explorado uso de los enigmas, cfr. Guichard (2007: 234). 22. Naerebout y Beerden (2013: 122). Véase también Parke y Wormell (1956: xxvii- xxviii). El estilo enigmático de los mensajes de los oráculos inspiró el uso filosófico de este tipo de composiciones que se ve, por ejemplo, en los aforismos de Heráclito, quien adopta deliberadamente una modalidad discursiva similar a la del oráculo de Delfos. Así se desprende de Plutarco, Sobre por qué la Pitia no proclama actualmente sus oráculos en verso 404d (DK 22 B 93): "El señor, cuyo oráculo es el de Delfos, ni dice ni oculta, sino que da signos (semaínel)". Sobre este tema, cfr. Maurizio (2013: 100-120) y Chitwood (1995: 49-62). 23. El trabajo más completo sobre este tema es el de Luz (2010). La forma griega tekhnopaignia no está atestiguada en ninguna fuente antigua. Ausonio emplea la forma gráfica latina technopaegnion para titular un poema de su autoría en el que la sílaba final de cada verso coincide con la sílaba inicial del verso siguiente.

24. Véase otros ejemplos en $A n$ tología palatina XIV.31, 35, 46. 
25. De la pieza de Alexis no se sabe nada, salvo que allí se mencionada a Sinope, una prostituta (Ateneo, Banquete de los sabios X.585f-586a = fr. $109 \mathrm{KA}$ ).

26. Como defiende Bianchi (2017: 115). Cfr. Homero, Odisea III.434. Para un análisis completo de todos los fragmentos conservados de la comedia Cleobulinas, véase Matelli (1997: 23-32).

27. Ateneo, Banquete de los sabios X.451bc (fr. 49 KA): "En Teseo, Dífilo cuenta que tres muchachas samias resuelven enigmas

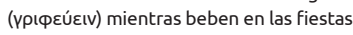
de Adonis. Se les lanza este enigma: '¿cuál es la cosa más dura de todas?'. Una responde que es el hierro y aporta una prueba para su respuesta, dado que con este las personas cavan, cortan y lo usan para todo. Una vez que es aprobada, se trae a la segunda, quien dice que el bronce tiene una dureza mucho más resistente, dado que, mientras ejecuta su trabajo, curva el fuerte hierro, lo reblandece y hace lo que quiere con él. Pero la tercera declara que el pene es la cosa más dura de todas y, lamentándose por el bronce, enseña que aquel se usa para la penetración anal". Cfr. Plutarco, Cuestiones convivales

717a, quien agrega que en Agrionia, el festival en honor de Dioniso celebrado en Beocia, las mujeres "al final de la cena, se lanzan unas a otras acertijos y enigmas"

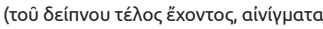

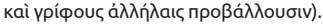

28. Según el comentario de Zenobio I.33, la metáfora del peplo ardiente se usa también para referir a las personas que promueven la sedición, enardeciendo los ánimos de la gente, desacreditando las instituciones políticas y formulando falsas acusaciones. Esto ocurrió, por ejemplo, con las acusaciones de impiedad que los adversarios de Pericles promovieron contra Aspasia, Fidias y Anaxágoras, a fin de desestabilizar su gobierno. Cfr. Matelli (1997: 27).

29. Plutarco, Vida de Pericles 24.9 (fr. 259

KA.): "En las comedias Aspasia es llamada Nueva Ónfale, Deyanira y también Hera. Cratino la ha llamado directamente 'prostituta' en los siguientes versos: 'al igual que a Hera, el inmundo deseo dio a luz a Aspasia, prostituta ojos de perro"'.

\section{Las mujeres y los enigmas en la comedia}

En los fragmentos conservados de algunas comedias, aparecen mujeres enunciando enigmas. Esto sería un indicio de que para los griegos la naturaleza femenina era vista como un acertijo indescifrable. Según defiende Martin (2001: 73), "cuando hablan, pronuncian enigmas porque ellas mismas son enigmas. Las Musas hesiódicas, la Pitia de Delfos y la mítica cantora de enigmas, la Esfinge, son paradigmas de este comportamiento". Como se verá a continuación, algunas de ellas son mujeres conocidas, como Cleobulina o la misma Safo, cuya labor intelectual es objeto de burla por parte de los comediógrafos. En ciertos casos, la burla se asocia con la presentación de dichas mujeres como personajes lascivos.

Por una parte, la figura de Cleobulina fue parodiada en dos comedias que llevan por título su nombre: Cleobulinas de Cratino y Cleobulina de Alexis. ${ }^{25}$ Se cree que el coro de la obra de Cratino habría estado compuesto, o bien de seguidoras de la poeta, o bien de mujeres que, como ella, se dedicaban a la formulación de acertijos. Una de las diez referencias que se conservan sobre la pieza se parece a un acertijo de contenido probablemente erótico que evoca la confección de herraduras y el acto de clavarlas en los cascos de las yeguas: "El joven varón tiene yunque y mar-

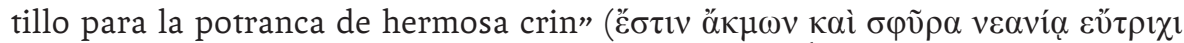
$\pi \omega \dot{\lambda} \omega)$ (Hefestión, Manual de métrica I 9 = fr. $94 \mathrm{KA}) .{ }^{26} \mathrm{El}$ contenido erótico del acertijo sugiere que Cleobulina habría sido representada en la pieza como una mujer impúdica y lujuriosa, semejante a las muchachas samias que en Teseo, la comedia de Dífilo, resuelven un enigma de contenido obsceno mientras beben en el festival de Adonis. ${ }^{27}$ Asimismo, en la pieza de Cratino se habría empleado la

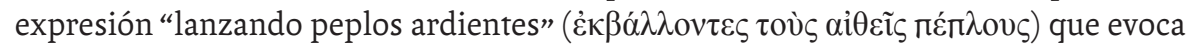
el conocido episodio de la muerte de Heracles cuyo cuerpo se quemó cuando se colocó la túnica impregnada por Deyanira con la sangre de Neso (Hesiquio, A 1861 $=$ fr. $95 \mathrm{KA}$ ). Se podría pensar que esta metáfora refiere al acto de proponer enigmas, ya que, como testimonia Plutarco, estos también se lanzan o disparan $(\delta 1 \alpha \beta \alpha ́ \lambda \lambda \varepsilon \tau \tau \alpha 1$, $\pi \rho o \varepsilon ́ \beta \alpha \lambda \varepsilon v)$ (Banquete de los siete sabios 148d, 154b). ${ }^{28}$ Asimismo, dado que Aspasia era llamada Deyanira, se podría sugerir que la del peplo ardiente era una metáfora utilizada por Cratino para criticar a la esposa de Pericles, quien podría también haber sido aludida en Cleobulinas. ${ }^{29}$

Por otra parte, en Sueño Alexis habría presentado a una mujer proponiendo a una muchacha un enigma sobre el sueño:
A: No es ni mortal ni inmortal, sino que tiene una mezcla de los dos, de modo que no vive completamente ni en la región del hombre ni en la del dios, sino que siempre nace de nuevo y su presencia se consume otra vez, es invisible a la vista, a pesar de ser conocido por todos.
B: Tú siempre te alegras, ¡oh, mujer!, de problematizarme con enigmas ( $\mu$ ' aivíyuari).
A: En verdad, proclamo comprender cosas simples y manifiestas.
B: ¿Qué criatura tendrá tal naturaleza?
$A$ : El sueño que alivia, joh, muchacha!, las fatigas de los mortales
(Ateneo, Banquete de los sabios X.449d-e = fr. $242 \mathrm{KA}$ ).

La conexión entre el sueño y la muerte se remonta a los orígenes de la literatura griega. Homero los presenta como hermanos gemelos cuya función es escoltar a los muertos (Ilíada XIV.231, XVI.672, 682). Hesíodo, en cambio, les atribuye distintas funciones: aunque ambos son hijos de la noche, el sueño habita en la región de los mortales y es dulce para los hombres, mientras que la muerte, de corazón de hierro, 
resulta odiosa incluso para los dioses (Teogonía 758-766). En el acertijo citado, el sueño se presenta como una entidad intermedia, ni mortal ni inmortal, que habita entre dioses y hombres. Su carácter invisible es también evocado en la versión del enigma del sueño de Antología palatina: "Si alguien mira, no me ve; pero si no mira, me ve. / El que no habla habla, el que no corre corre. / Soy tramposo, pero digo todas cosas verdaderas" (XIV.110). También es llamativo que en la comedia de Alexis los enigmas sean asociados con la comprensión de lo simple y manifiesto. En efecto, como se aclaró supra, la solución de la mayor parte de los acertijos refiere a fenómenos o entidades del mundo cotidiano, y su función es, mediante enunciados de difícil comprensión, ocultarlos con el fin de poner en cuestión el presunto conocimiento que tenemos sobre ellos.

Por otra parte, en Tragedia del alfabeto Calias menciona un acertijo pronunciado por una mujer a unas compañeras: ${ }^{30}$

¡Oh, mujeres! Estoy embarazada. Con vergüenza, queridas, diré abiertamente el nombre del crío por medio de sus letras: hay una larga línea recta y en el centro se coloca, a cada lado, una línea horizontal corta.

Luego, hay un círculo con dos pies pequeños

(Ateneo, Banquete de los sabios X.454a = test. $7 \mathrm{KA}$ ).

Como se desprende del testimonio de Ateneo, en la obra de Calias se citarían numerosos acertijos. ${ }^{31} \mathrm{El}$ coro habría estado integrado por letras del alfabeto griego, de ahí que el acertijo citado refiera a la $\Psi$ y a la $\Omega$ que juntas mostrarían el inicio de una

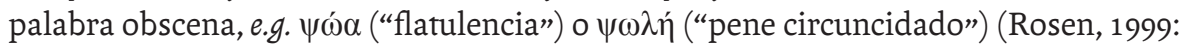
156, n. 20; Ruijgh, 2001: 259). También es probable que la grafía de las letras inspirara la realización de movimientos impúdicos en escena (Svenbro, 1993: 185). Este acertijo se conecta directamente con el de Safo, ya que presenta a las letras como las crías de una mujer.

\section{El enigma de Safo}

Safo, la comedia de Antífanes, podría haber sido escrita entre 370 y 350 a. C. De la pieza sólo se conservan dos fragmentos. Me interesa aquí detenerme en el fr. 194 KA, extraído del décimo libro de Banquete de los sabios que Ateneo de Náucratis dedica a la presentación de numerosos enigmas (X.450e-451b). Es probable que este no conociera de primera mano la comedia de Antífanes, sino que tomara el enigma de la colección de Clearco de Solos, una de las principales fuentes utilizadas para la composición del libro décimo (Ceccarelli, 2004: 12, n. 2).

En la comedia el personaje de Safo pronuncia el siguiente enigma:

Safo: Existe una criatura femenina que protege a sus crías en su propio vientre.

Aunque mudas, a través del oleaje del mar y de la tierra firme toda,

ellas lanzan un grito resonante

a cualquier mortal que deseen.

Es posible que las escuchen quienes no están presentes, aunque sean sordos.
30. La comedia, referida también por Ateneo como Espectáculo de las

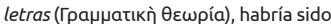
compuesta por Calias de Atenas y pertenecería al período de la llamada "comedia antigua". Al respecto, cfr. Kassel y Austin (1983: 38-40) y Rosen (1999: 147-149).

31. Ateneo, Banquete de los sabios X.448bc: "Para nosotros, amigos, es momento de investigar un poco sobre los enigmas, para que nos apartemos de los vasos, aunque sea por poco tiempo, pero no como establece La tragedia del alfabeto escrita por Calias de Atenas. Investiguemos nosotros cuál es la definición de 'enigma', no cuál lanzó Cleobulina de Lindos en sus acertijos, pues nuestro compañero, Diotimo de Olimpene, ha hablado suficientemente sobre eso, sino cómo los compositores de comedias se han ocupado de ellos y qué prenda esperaban quienes no pudieran resolverlos". Según la hipótesis de Rosen (1999: 159-166), la obra misma de Calias habría sido concebida como un enigma que desafía los límites del género trágico.

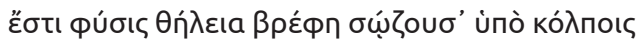

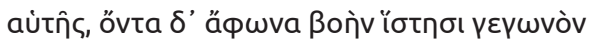

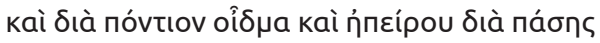

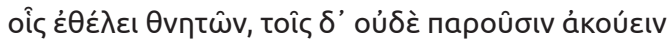

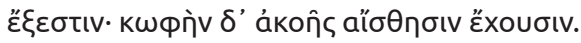


32. Aristóteles, Constitución de los atenienses 45.4. Cfr. Buis (2014: 58, n. 23).
Este enigma se ajusta a la definición propuesta por Aristóteles: presenta nociones opuestas - criaturas mudas que profieren gritos resonantes y personas que pueden escuchar, aunque sean sordas- para referir a una entidad realmente existente. Del acertijo se ofrecen dos soluciones. La primera es propuesta por el personaje que en la comedia representaría al padre de Safo: la criatura femenina es la ciudad y sus crías, los oradores que, gritándose unos a otros, se reparten el dinero que ganan ante un pueblo que no comprende lo que estos realmente hacen y dicen:

Padre: La criatura de la que hablas es la ciudad que alimenta dentro de sí a sus crías, los oradores.

Estos, gritando, desde Asia y Tracia

arrastran hasta aquí sus ganancias de ultramar.

Mientras se las reparten y se agravian constantemente,

se sienta cerca de ellos el pueblo,

sin escuchar ni ver nada.

Safo: <...> ¿Pero cómo podría existir, padre,

un orador mudo? Padre: Si acaso es atrapado tres veces actuando en contra de

la ley.

$<. . .>$ Creo conocer con exactitud

lo que se ha dicho, pero habla tú.

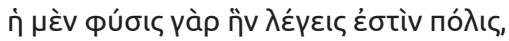

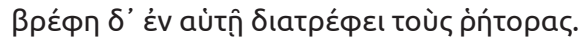

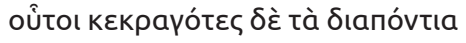

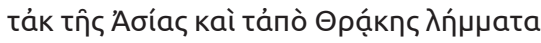

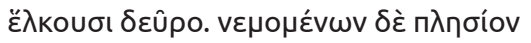

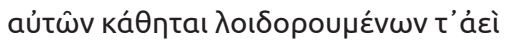

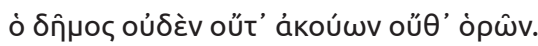

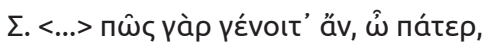

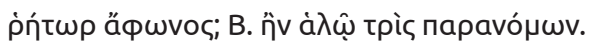

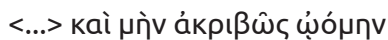

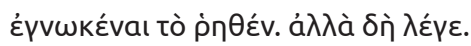

La solución que propone el padre es rechazada por Safo. Los oradores no podrían ser crías mudas porque la palabra hablada es su herramienta de trabajo: hablan y enseñan a hablar a cambio de dinero. Para replicar a esta objeción, el padre hace referencia a la acción judicial pública que podía ser iniciada contra quien proponía un decreto ilegal: aquel que fuera condenado tres veces por esta acción era privado de sus derechos cívicos y, por lo tanto, dejado sin voz. Esto podría explicar por qué algunos oradores podrían ser considerados criaturas mudas. ${ }^{32}$

Safo contesta a su padre aportando la verdadera solución del enigma:

Safo: Y bien, la criatura femenina es la carta

que lleva dentro de sí a sus crías, las letras.

Aunque mudas, estas hablan a quienes están lejos,

a cualquiera que deseen,

y puede suceder que alguien,

aunque esté casualmente cerca del que lee, no escuche

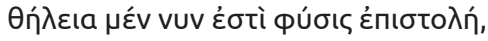

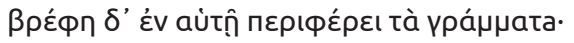

äథwva $\delta$ ' óvta <taûta> toîs nó $\rho \omega \lambda \lambda \lambda \lambda \varepsilon \hat{\imath}$

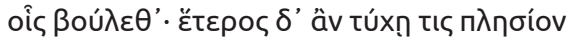

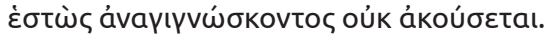


De acuerdo con la respuesta de Safo, la criatura femenina es la carta y sus crías, las letras que forman las palabras escritas. Lo interesante del enigma es que presenta la palabra oral como una metáfora de la palabra escrita: aunque las letras escritas son mudas, tienen la capacidad de "hablar" - i.e. comunicar - a quienes las leen. Por eso "hablan" a quienes quieren - i.e. a los destinarios del mensaje- y pueden ser "escuchadas" - i.e. leídas- por quienes están lejos, están ausentes o son sordos.

De la comparación entre las dos respuestas al enigma, surge una serie de oposiciones que permiten caracterizar dos modos de comunicación: por una parte, la comunicación oral, de carácter público, propia de los oradores que se enriquecen en las ciudades proclamando abiertamente discursos que el pueblo no comprende; por otra parte, la comunicación escrita, de carácter íntimo, propia de quienes redactan epístolas cuyo contenido privado sólo puede ser comprendido por los destinatarios que leen el mensaje. 33

De la respuesta de Safo se han ofrecido diversas interpretaciones. En primer lugar, se ha señalado que esta permite comprender, en el marco del pasaje de la cultura de la oralidad a la cultura de la escritura, la irrupción del género epistolar y la práctica extendida de la lectura silenciosa. En opinión de Knox (1968: 434), testimonios como el de Antífanes demuestran claramente que en los siglos V y IV "la lectura silenciosa de cartas y oráculos ( $\mathrm{y}$, por consiguiente, de cualquier documento breve) era un hecho" (cfr. Gavrilov, 1997: 68). En segundo lugar, se ha señalado que el enigma de Safo defiende un nuevo modo de comunicación asociado con lo femenino y representado a través de la carta, que desafía el orden simbólico dominante. En efecto, según defiende Rosenmeyer (2001: 96), la carta es vista como "un documento de secreto y protección en contraste con el modo de comunicación convencional, directo y oral, asociado con los varones y la orden militar" (cfr. Skinner, 1993: 131). De la escritura de epístolas por parte de mujeres, da testimonio Eurípides en algunas tragedias que servirían como horizonte de referencia del enigma de Safo. ${ }^{34}$ En Ifigenia entre los tauros la muchacha del mismo nombre escribe en una tablilla un mensaje para su familia en Argos, que tiene la capacidad de franquear las distancias y comunicar sus palabras: "si acaso logras mantener a salvo la carta, / esta misma comunicará en silencio ( $\varphi \rho \alpha ́ \sigma \varepsilon \imath ~ \sigma \iota \gamma \tilde{\omega} \sigma \alpha)$ lo que ha sido escrito" (762-763). En Hipólito Fedra se suicida y deja escrito un mensaje que grita (ßoôa) a Teseo que su hijo intentó seducirla $(856-865,877)$. En estas dos últimas tragedias, los mensajes escritos personifican a las mujeres que son sus autoras (Rosenmeyer, 2001: 96). En conjunto, ambos testimonios hacen referencia a la paradójica característica de la epístola señalada en el enigma de Safo: su capacidad de gritar, i.e. de comunicar, en silencio.

Asimismo, como sugiere Williamson (1995: 15), la valoración positiva que Safo hace de la escritura contrasta con las críticas de Platón, quien en el Fedro presenta los discursos escritos como vástagos débiles que necesitan siempre de la ayuda de su progenitor -i.e. el autor del discurso escrito-: "cuando es ofendido o maltratado injustamente

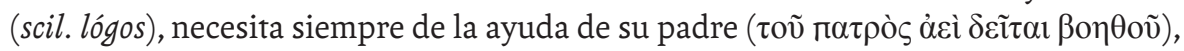
pues no puede defenderse y ayudarse a sí mismo" (275e). Dado que, una vez escrito, el discurso puede ser leído por quienes lo entienden y quienes no, existe el peligro de que sea injustamente criticado. Como este es incapaz de defenderse, ya que "guarda silencio muy solemnemente" ( $\sigma \varepsilon \mu \nu \tilde{\omega} \varsigma$ กóvv $\sigma \gamma \gamma \tilde{\alpha})$ o "sólo indica una sola cosa, siem-

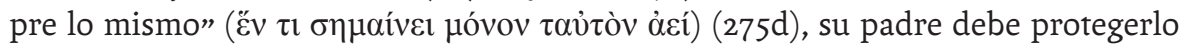
de las críticas injustas y dar las respuestas a las preguntas que no puede contestar. El discurso oral, en cambio, sabe distinguir a quien dirigirse, ayudarse a sí mismo y enseñar la verdad (276a-c). El acertijo de Safo invierte la valoración platónica: mientras la palabra oral es empleada para el agravio y se vuelve incomprensible para quienes escuchan, las palabras escritas son concebidas como potentes criaturas que custodian mensajes y los transportan hacia los remitentes que los esperan.
33. De acuerdo con la opinión de Ceccarelli (2013: 250-257), las dos soluciones del enigma son válidas y permitirían a Antífanes criticar tanto el modo de comunicación de los oradores como el epistolar.
34. Un tratamiento extenso de este tema se encuentra en Rosenmeyer (2001: 61-97) y Ceccarelli (2013: 183-258). 
35. Sigo el texto fijado por Wilamowitz (1919: 71), salvo en el primer verso, donde reemplazo la variante 'ยع

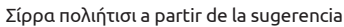
hecha por Plant (2004: 44, n. 8).
En tercer lugar, el enigma del personaje Safo ha sido utilizado para interpretar algunos de los versos de la Safo histórica. Svenbro (1993: 145-159) lo toma como referencia para realizar una exégesis alegórica del fr. 31 según la cual la primera persona que habla es Safo, la mujer a la que le habla, el poema y la tercera persona, el lector o lectora. El enigma también ha servido para comprender el proceso de composición poética de la propia Safo y el valor de su producción literaria. En el epigrama que Dioscórides compone sobre ella, se utiliza la misma analogía que en el enigma de Antífanes y se compara a sus versos con sus hijas: "En cualquier lugar, te saludo, venerable, semejante a los dioses; / pues aún ahora tenemos tus poemas como tus hijas inmortales" (Antología palatina VII.407 = test. 58 Campbell). La carta simbolizaría los versos de la propia Safo que tienen la capacidad de extenderse por el mundo guardando un mensaje íntimo que llega a quienes están lejos (Martin, 2001: 74). Asimismo, el acertijo podría servir como metáfora de la producción literaria de las mujeres de la Antigüedad. En efecto, la maternidad es una metáfora de la autoría femenina que aparece no sólo en el acertijo de Safo, sino también en el único epigrama votivo de Eurídice de Macedonia del que tenemos conocimiento:

Eurídice, ciudadana de Sirra, ofrece esto a las Musas

luego de alcanzar con el alma el deseo de conocer.

Después de haberse convertido en madre de hijos fuertes,

trabajó duro para aprender las letras, recordatorio de las palabras.

(Plutarco, Sobre la educación de los niños 14c).

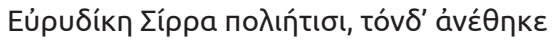

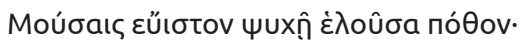

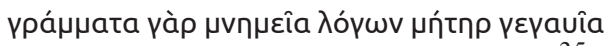

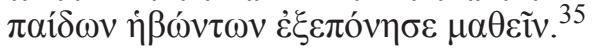

Plutarco presenta a Eurídice como un modelo de madre que aprendió a leer y escribir sólo para instruir a sus hijos, Alejandro II, Pérdicas III, Filipo II y Eurínome. No obstante, los versos de Eurídice sugieren otra cosa: ella anuncia orgullosa que ha aprendido a leer y a escribir tarde, luego de ser madre, para satisfacer el deseo de conocimiento de su propia alma (Plant, 2004: 44). Aún más, la relación con la escritura transforma y redefine la función materna: no sólo es madre de sus hijos, sino que, gracias al aprendizaje, logra también serlo de las palabras (Hauser, 2016: 150). Esto está sugerido en el tercer verso del epigrama a través de la ambigua posición de $\lambda o ́ \gamma \omega v$ que puede ser complemento de especificación de $\mu v \eta \mu \varepsilon i \alpha$ ("recordatorio de

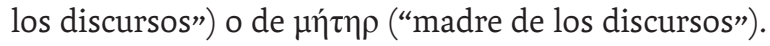

En cuarto lugar, me gustaría sugerir una línea de lectura alternativa, pero complementaria a las ya presentadas. Aunque la solución del acertijo de Safo sea la carta, este también podría referir al modo de comunicación propio de los enigmas. La poeta compone un enigma sobre la carta porque la carta podría ser comprendida como una metáfora del enigma. Las palabras escritas que las epístolas guardan tienen la capacidad de hablar en silencio: sin que medie la voz, son capaces de transmitir mensajes a sus destinatarios. De cierta manera, los acertijos también comparten esta característica. Aunque a través de múltiples estrategias retóricolingüísticas esconden su solución, las pistas que ofrecen pueden ser concebidas como esos gritos resonantes cuyo sentido sólo puede ser comprendido cabalmente por quienes logran resolverlos. Así, la capacidad de hablar callando que es propia de la carta se muestra análoga al modo de comunicación que caracteriza a los enigmas: revelar ocultando. 


\section{Conclusión}

El enigma que Antífanes atribuye a Safo presenta las características generales de este tipo de composiciones. A través del recurso de la analogía, establece una comparación entre una madre y sus crías, y la carta y las letras; a través de la presentación de nociones opuestas, intenta describir el modo de comunicación propio de las palabras escritas que consiste en hablar (i.e. transmitir mensajes) callando (i.e. sin que medie la voz). Una vez más, aunque la solución consiste en un objeto familiar y conocido, la oscuridad propia del enunciado enigmático dificulta su hallazgo.

De acuerdo con la opinión de Wittgenstein referida al comienzo del artículo, un enigma podría ser comprendido como una pseudo-proposición que oculta su referente de manera tal que, antes de conocer la solución, posee sólo un sentido promisorio. Aunque muchas fuentes antiguas transmiten no sólo los enigmas, sino también las soluciones que les corresponden, nada impide que podamos encontrar, aún hoy, respuestas alternativas para acertijos antiguos. Por esta razón, he defendido que, aunque la solución del enigma que Antífanes atribuye a Safo sea la carta, este también podría referir al enigma y al modo en que un enigma se compone y transmite. De cierta manera, estos también son criaturas que hablan (i.e. comunican) a través de pistas, mientras callan (i.e. esconden) su solución a través de enunciados ambiguos o contradictorios.

Por otra parte, al igual que la carta, el enigma también simboliza el modo de comunicación alternativo asociado con lo femenino que desafía el orden simbólico dominante, lo que explicaría por qué en los fragmentos de comedias que hemos referido las mujeres aparecen pronunciando acertijos. En oposición al discurso claro y transparente que busca referir a las entidades del mundo sin ambigüedad, el enigma explota la oscuridad y ambivalencia de enunciados polisémicos que revelan sus referentes al tiempo que los ocultan. 


\section{Q Bibliografía}

" Beckby, H. (1958). Anthologia Graeca. Vol. 4: Buch XII-XVI. Munich: Heimeran.

" Berra, A. (2008). Théorie et pratique de l'énigme en Grèce ancienne. París: École des Hautes Études en Sciences Sociales.

» Beta, S. (2009). Riddling at table: trivial ainigmata vs. philosophical problemata. En J. Ribeiro Ferreira, D. Leão, M. Tröster y P. Barata Dias (eds.), Symposion and Philanthropia in Plutarch (pp. 97-102). Coimbra: Centro de Estudos Clássicos e Humanísticos.

"Beta, S. (2016). Il labirinto della parola. Enigmi, oracoli e sogni nella cultura antica. Turín: Einaudi.

" Bianchi, F. (2017). Fragmenta Comica. Kratinos, Einleitung und Testimonia. Band 3.1. Heidelberg: Verlag Antike.

» Buis, E. (2014). De madres, ciudades y tablillas: alcances políticos y literarios de un enigma familiar en la comedia media (Antífanes, Safo, fr. 194 KA). Stylos, 23, pp. 48-69.

" Buffière, F. (1970). Anthologie grecque. Première partie: Anthologie palatine. Tomo XII: livres XIII-XV. París: Les Belles Lettres.

» Burton, J. (1998). Women's Commensality in the Ancient Greek World. Greece \& Rome, 45, pp. 143-165.

" Ceccarelli, P. (2004). Écriture féminine, écriture épistolaire, parole des rhétheurs: à propos du fr. 194 KA de la Sappho d'Antiphane. En L. Nadjo y E. Gavoille (eds.), Epistulae antiquae (pp. 11-32). Vol. II. Lovaina: Peeters.

»Ceccarelli, P. (2013). Ancient Greek Letter Writing: A Cultural History (600 BC-150 BC). Nueva York: Oxford University Press.

"Chitwood, A. (1995). Heraclitus aivıxtńc. Heraclitus and the Riddle. Studi Classici e Orientali, 43, pp. 49-62.

» Gardella, M. y Juliá, V. (2018). El enigma de Cleobulina. Buenos Aires: Teseo.

" Gavrilov, A. K. (1997). Techniques of Reading in Classical Antiquity. The Classical Quarterly, 47 (1), pp. 56-73.

"Guichard, L. (2007). Acertijos de uso escolar en papiros, tablillas y óstraka. En J. Fernández Delgado, F. Pordomingo Pardo y A. Stramaglia (eds.), Escuela y literatura en Grecia antigua (pp. 225-236). Salamanca: Ediciones Universidad de Salamanca.

" Guichard, L. (2010). Acerca del tratado Perì gríphon de Clearco de Solos. En F. Cortés Gabaudán y J. Méndez Dosuna (ed.), Dic mihi, Musa, virum. Homenaje al Profesor Antonio López Eire (pp. 285-291). Salamanca, Ediciones Universidad de Salamanca.

» Hasan-Rokem, G. y Shulman, D. (eds.) (1996). Untying the Knot: On Riddles and Other Enigmatic Modes. Nueva York: Oxford University Press.

» Hauser, E. (2016). In Her Own Words: The Semantics of Female Authorship in Ancient Greece, from Sappho to Nossis. Ramus, 45 (2), pp.133-164.

" Kaivola-Bregenhøj, A. (2001). Riddles: Perspectives on the Use, Function, and Change in a Folklore Genre. Helsinki: Finnish Literature Society. 
" Kassel, R. y Austin, C. (1983-2001) [KA]. Poetae Comici Graeci. 8 vols. Berlín: De Gruyter.

»Katz, J. (2006). The Riddle of the sp(h)ij-: The Greek Sphinx and Her Indic and IndoEuropean Background. En G. J. Pinault y D. Petit (eds.). La langue poétique indoeuropéenne: Actes du Colloque de travail de la Société des Études Indo-Européennes (pp. 157-194). Lovaina: Peeters.

» Knox, B. M. W. (1968). Silent Reading in Antiquity. Greek, Roman and Byzantine Studies, 9, pp. 421-435.

"Konstantakos, I. M. (2004). Trial by Riddle: The Testing of the Counsellor and the Contest of Kings in the Legend of Amasis and Bias. Classica et Mediaevalia, 55, pp. 85-138.

» Luz, C. (2010). Technopaignia. Formspiele in der griechischen Dichtung. Leiden: Brill.

» Luz, C. (2013). What Has It Got in Its Pocketses? Or, What Makes a Riddle a Riddle?. En J. Kwapisz, D. Petrain y M. Szymański (eds.), The Muse at Play: Riddles and Wordplay in Greek and Latin Poetry (pp. 83-99). Berlín: De Gruyter.

» Martin, R. P. (2001). Just Like a Woman: Enigmas of the Lyric Voice. En A. Lardinois y L. McClure (eds.), Making Silence Speak. Women's voices in Greek Literature and Society (pp. 55-74). Princeton: Princeton University Press.

"Matelli, E. (1997). Sulle tracce di Cleobulina. Aevum, 71, pp. 11-61.

" Maurizio, L. (2013). Technopaegnia in Heraclitus and the Delphic Oracles: Shared Compositional Techniques. En J. Kwapisz, D. Petrain y M. Szymański (eds.), The Muse at Play: Riddles and Wordplay in Greek and Latin Poetry (pp. 100-120). Berlín: De Gruyter.

"Naerebout, F. y Beerden, K. (2013). "Gods Cannot Tell Lies": Riddling and Ancient Greek Divination. En J. Kwapisz, D. Petrain y M. Szymański (eds.), The Muse at Play: Riddles and Wordplay in Greek and Latin Poetry (pp. 121-147). Berlín: De Gruyter.

»Parke, H. y Wormell, D. (1956). The Delphic Oracle. Vol. 1: The History. Oxford: Blackwell.

»Plant, I. (2004). Women Writers of Ancient Greece and Rome. An Anthology. Norman: University of Oklahoma Press.

»Potamiti, A. (2015). vpíфous naílદıv: Playing at Riddles in Greek. Greek, Roman, and Byzantine Studies, 55, pp. 133-153.

» Pucci, P. (1996). Enigma, segreto, oracolo. Pisa: Istituti Editoriali e Poligrafici Internazionali.

» Rokem, F. (1996). One Voice and Many Legs: Oedipus and the Riddle of the Sphinx. En G. Hasan-Rokem y D. Shulman (eds.), Untying the Knot: On Riddles and Other Enigmatic Modes (pp. 255-270). Nueva York: Oxford University Press.

» Rosen, R. (1999). Comedy and Confusion in Callias' Letter Tragedy. Classical Philology, 94, pp. 147-167.

" Rosenmeyer, P. A. (2001). Ancient Epistolary Fictions: The Letter in Greek Literature. Cambridge: Cambridge University Press.

» Ruijgh, C. J. (2001). Le Spectacle des lettres, comédie de Callias (Athénée X.453c455b), avec un excursus sur les rapports entre la mélodie du chant et les contours mélodiques du langage parlé. Mnemosyne, 54 (3), pp. 257-335.

"Segal, C. (1999). Tragedy and Civilization: An Interpretation of Sophocles. Norman: University of Oklahoma Press. 
"Skinner, M. B. (1993). Woman and Language in Archaic Greece, or, Why Is Sappho a Woman? En N. Sorkin Rabinowitz y A. Richlin (eds.), Feminist Theory and the Classics (pp. 125-144). Nueva York: Routledge.

"Svenbro, J. (1993). Phrasikleia: An Anthropology of Reading in Ancient Greece. Ithaca: Cornell University Press.

» Taylor, A. (1943). The riddle. California Folklore Quarterly, 2, pp. 129-147.

» Taylor, A. (1951). English Riddles from Oral Tradition. Los Ángeles: Octagon Books.

»Vernant, J. P. (1990). Ambiguity and Reversal: On the Enigmatic Structure of Oedipus Rex. En J. P. Vernant y P. Vidal-Naquet, Myth and Tragedy in Ancient Greece (pp. 113-140). Nueva York: Zone Books.

»Wehrli, F. (1968). Die Schule des Aristoteles. Vol. III: Klearches. Basilea: Schwabe.

»Wilamowitz, U. (1919). Lesefrüchte. Hermes, 54 (1), pp. 46-74.

"Williamson, M. (1995). Sappho's Immortal Daughters. Massachusetts: Harvard University Press. 